\title{
Mixed type of hiatus hernia: incidental diagnosis of a potentially life-threatening condition
}

\author{
Kritika Sharma, ${ }^{1}$ Rajaram Sharma $10,{ }^{2}$ Tapendra Tiwari, ${ }^{2}$ Saurabh Goyal ${ }^{2}$
}

'Department of Radiodiagnosis, Pacific Institute of Medical Sciences, Umarda, Udaipur, Rajasthan, India

${ }^{2}$ Department of Radiology, Pacific Institute of Medical Sciences, Umarda, Udaipur, Rajasthan, India

\section{Correspondence to}

Dr Rajaram Sharma;

hemantgalaria13@gmail.com

Accepted 13 September 2021

\section{DESCRIPTION}

Hiatus hernia refers to a condition in which elements of the abdominal cavity, most commonly the stomach, herniate through the oesophageal hiatus into the mediastinum. The oesophageal hiatus is vulnerable to visceral herniation because it faces directly to the abdominal cavity and is subjected to pressure stresses between the two cavities. Broadly, hiatus hernias are of four types: type I, sliding hiatal hernia ( $95 \%)$, where the gastrooesophageal junction (GEJ) slides upwards; type II, paraoesophageal hiatal hernia $(\sim 5 \%)$, where the GEJ at its usual position and the gastric fundus roll

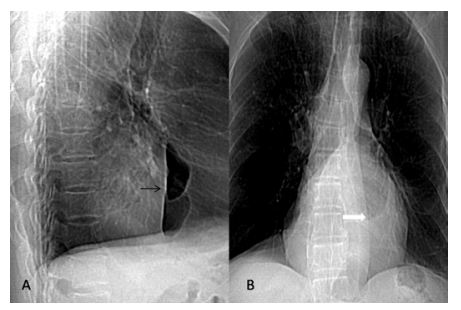

Figure 1 Plain scout radiograph of the chest. (A) Left lateral decubitus view shows areas of air-fluid levelling in the thoracic region in the middle mediastinum (black arrow). (B) Posteroanterior view shows lucency with the air-fluid level in the lower thoracic region, overlapping the cardiac shadow (white arrow).

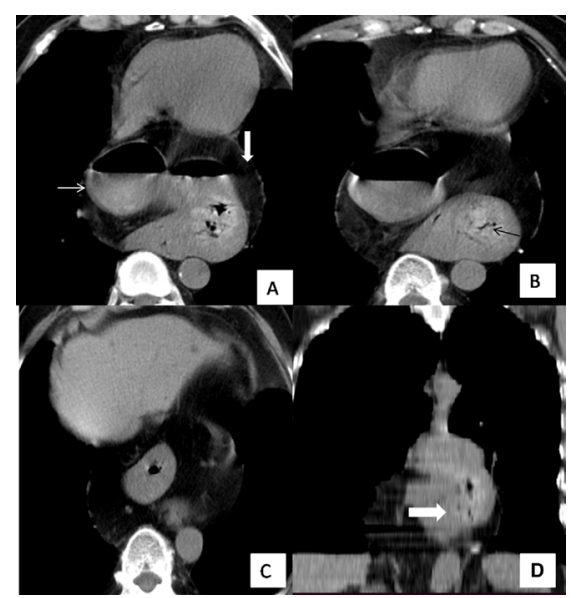

(C) BMJ Publishing Group Limited 2021. No commercial re-use. See rights and permissions. Published by BMJ.

To cite: Sharma K, Sharma R,
Tiwari T, et al. BMJ Case
Rep 2021;14:e245887.
doi:10.1136/bcr-2021-
245887

Figure 2 (A, B and C) CT scan axial plane images show widened oesophageal hiatus with cephalic migration of the gastro-oesophageal junction (black arrow) and herniation of the entire stomach into the thoracic cavity (white arrow) with surrounding fat (thick white arrow). (D) A reformatted coronal image shows widened oesophageal hiatus and herniation of the entire stomach into the thoracic cavity (thick white arrow).

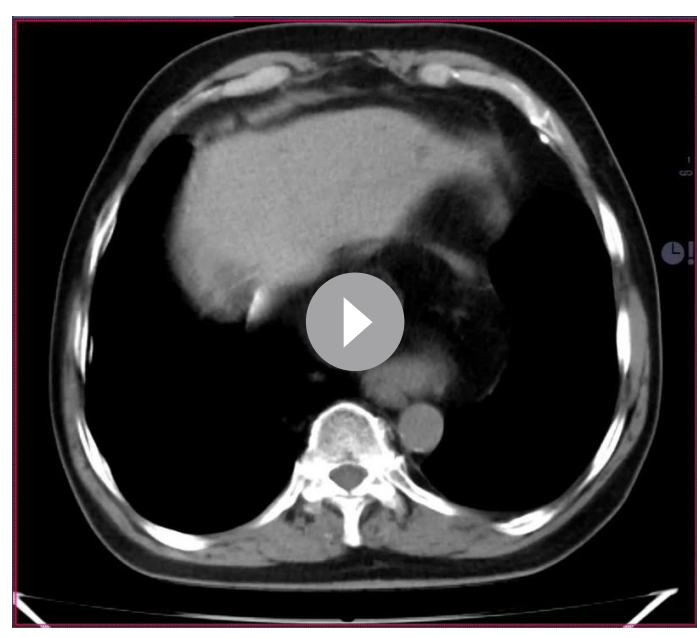

Video 1 CT scan, WMF video format. Axial plane, non-enhanced movie clip of the lower thorax and upper abdomen shows upward displacement of the entire stomach into the thoracic cavity (in retrocardiac region/ middle mediastinum) with cephalic migration of the gastro-oesophageal junction.

upwards through the widened hiatus; type III, the mixed type, where there is herniation of the cardiac and fundus part of the stomach, along with sliding of the GEJ upwards; and type IV, which includes herniation of the entire stomach into the thorax, leading to an upside-down orientation of the stomach. Types III and IV constitute approximately $5 \%$ of all hernias. The most significant hiatal defect is noted in type IV. ${ }^{1}$ Large paraoesophageal hernias, with most of the stomach in the thorax, increase the risk of complications such as volvulus, obstruction and ischaemia. ${ }^{2}$ Large hiatal hernias rarely present with a gastro-oesophageal reflux disease manifestation in most patients, so either $\mathrm{pH}$ metre or $\mathrm{pH}$ impedance alone is superfluous during presurgical management. CT with an oral contrast agent is ideally recommended whenever type III/IV hernia is suspected. ${ }^{3}$ Laparoscopic fundoplication is the standard treatment to restore the function of the lower oesophageal sphincter by wrapping the stomach around the oesophagus. ${ }^{4}$ However, the approach of surgical treatment of large hernias can be challenging. The main technical concern is relocating the hernial contents into the abdominal cavity, repairing large diaphragmatic defects, dissection of adhesions with the abdomen and the mediastinum, and occasionally shortening of the oesophagus. The use of mesh for support and cruroplasty is decided intraoperatively. ${ }^{3}$ 
On CT scan, classic features are seen, such as as the omentum herniating through the junction into the middle mediastinum, widened oesophageal hiatus, dehiscence of the diaphragmatic crura $(>15 \mathrm{~mm})$, and increased distance between the crura and the oesophageal wall. Additionally, a CT scan will help visualise the distal oesophagus, sac content, and size and orientation of the herniated stomach in the sac.

A 55-year-old man came to us with complaints of breathing difficulty, recurrent vomiting, heart burn and loss of appetite. ${ }^{5}$ Echocardiography was done in the emergency room and was unremarkable. The emergency medical officer prescribed a radiograph of the chest for breathing difficulty and revealed a double-pocket-like lucency in the lower thoracic region with an air-fluid level (white arrow in figure 1). Based on these radiographic features, the surgeon suspected a hiatus hernia, and lung abscess was kept as a differential diagnosis. As the patient had persistent vomiting and breathing difficulty, barium examination

\section{Patient's perspective}

It was very difficult initially with breathlessness and heartburn symptoms. I could not even walk a bit, and after the initial radiograph, it was suspected some lung disease and advised further investigation like CT thorax. In CT scan, I was diagnosed with a Hiatus hernia and referred to surgery on an immediate basis.

\section{Learning points}

- Symptoms of mixed hiatus hernia may mimic symptoms of cardiopathy and need urgent attention.

- An unenhanced CT scan of the thorax, including the upper abdomen, is the ideal non-invasive imaging modality on an emergency basis to narrow the differential diagnosis and reach an accurate diagnosis.

- It is important to differentiate type III/IV hiatus hernia from other types in view of preoperative planning due to risk of entrapment of the abdominal viscera and manifestations related to compression of thoracic structures. or gastroscopy was not possible. To ascertain the final diagnosis between the differentials mentioned above, an emergency unenhanced CT scan of the thorax was performed as the next reasonable step. It showed herniation of the entire stomach into the thorax (white arrow in figure 2) through the hiatus with a displaced GEJ (black arrow in figure 2) (video 1). After all the initial battery of investigations, all the options were explained to the patient, and a decision for laparoscopic fundoplication was finally made. During the surgery, with the help of a Veress needle, pneumoperitoneum was achieved, and the operating surgeon noticed a large hiatal hernia containing the GEJ and almost the entire stomach into the thoracic cavity. The phrenooesophageal membrane was dissected with a harmonic scalpel, and the right crus of the diaphragm was bared. In the next step, the abdominal part of the oesophagus was mobilised, and cruroplasty was performed using interrupted sutures. Lastly, the fundus of the stomach was used for a $360^{\circ}$ wrap. The patient was kept on proton pump inhibitors and regular follow-up at monthly intervals. He is doing fine as of his recent follow-up.

Contributors KS and RS contributed to planning, conduct, reporting, conception and design, acquisition of data, or analysis and interpretation of data. SG and TT contributed to acquisition and interpretation of data.

Funding The authors have not declared a specific grant for this research from any funding agency in the public, commercial or not-for-profit sectors.

Competing interests None declared.

Patient consent for publication Obtained.

Provenance and peer review Not commissioned; externally peer reviewed.

ORCID iD

Rajaram Sharma http://orcid.org/0000-0003-1126-5875

\section{REFERENCES}

1 Skinner DB, Belsey RH. Surgical management of esophageal reflux and hiatus hernia. long-term results with 1,030 patients. J Thorac Cardiovasc Surg 1967;53:33-54.

2 Klein J, Vinson EN, Helms CA. Brant and Helms' fundamentals of diagnostic radiology, 2018. ISBN: 9781496367396

3 Migaczewski M, Grzesiak-Kuik A, Pędziwiatr M, et al. Laparoscopic treatment of type III and IV hiatal hernia - authors' experience. Wideochir Inne Tech Maloinwazyjne 2014;9:157-63.

4 Dąbrowski WP, Szczepanik AB, Misiak A, et al. Radiofrequency ablation in the management of barrett's esophagus - preliminary own experience. Wideochir Inne Tech Maloinwazyjne 2013;8:107-11.

5 Kahrilas PJ, Kim HC, Pandolfino JE. Approaches to the diagnosis and grading of hiatal hernia. Best Pract Res Clin Gastroenterol 2008:22:601-16.

Copyright 2021 BMJ Publishing Group. All rights reserved. For permission to reuse any of this content visit

https://www.bmj.com/company/products-services/rights-and-licensing/permissions/

BMJ Case Report Fellows may re-use this article for personal use and teaching without any further permission.

Become a Fellow of BMJ Case Reports today and you can:

- Submit as many cases as you like

- Enjoy fast sympathetic peer review and rapid publication of accepted articles

- Access all the published articles

Re-use any of the published material for personal use and teaching without further permission

Customer Service

If you have any further queries about your subscription, please contact our customer services team on +44 (0) 2071111105 or via email at support@bmj.com.

Visit casereports.bmj.com for more articles like this and to become a Fellow 